\title{
Consideration of the role of tourism environmental protection on the sustainable development of Tourism
}

\author{
Xiang Jia ${ }^{1}$ \\ ${ }^{1}$ Wuhan School of tourism and hotel management, Wuhan, Hubei, China
}

\begin{abstract}
Key words: tourism environmental protection; tourism; sustainable development; environmental coordination

Abstract:In this paper, in order to study the tourism environment protection as the core, to analyze the relationship between the sustainable development of tourism environmental protection and tourism, clear tourism environment protection value, and put forward the tourism environmental protection measures to promote the sustainable development of tourism, and provide some reference and help for the related researchers.
\end{abstract}

\section{Introduction}

As social economy and science and technology develop constantly, modernization construction has deemed sustainable development as the core strategy and has enhanced functions of population control, environment protection and resource saving to realize harmonious development between economic construction and environmental construction.

For tourism in China, tourism environmental protection is closely linked with the sustainable development of tourism; to promote the sustainable and healthy development of tourism in China, it shall well handle with the relation between economy and environment and enhance protection to tourism environment but not damage the environment to develop economy. From the perspective of overall situation, it should pay attention to environmental protection to obtain permanent interests for tourism, then to further promote the sustainable and healthy development of tourism. Under such background, exploring the functions of tourism environmental protection on sustainable development of tourism has important practical significance.

\section{Relationship between Tourism Environmental Protection and Sustainable Development of Tourism}

\section{Tourism environment provides material basis for tourism}

Environmental protection occupies a very important position in the sustainable development of tourism. Favorable environment provides material basis for the development of tourism; people will directly consume natural environment and cultural environment of tourism. Only landscape environment with favorable recirculating state could stimulate people' s desire to go on a journey, then turn such desire to demand for tourism consumption. Therefore, it is necessary to enhance tourism environmental protection, improve tourism ecological environment, enrich natural ecological resources and historical culture resources to boost tourist attraction and realize harmonious development between environment and tourism.

\section{Tourism environment provides development direction for tourism}

Natural environment leads development direction for tourism, because tourism highly depends on natural environment. Under the environment that people' $\mathrm{s}$ consumption concept and power of consumption are improved gradually, people' $\mathrm{s}$ aesthetic demand on natural environment is also enhanced increasingly; tourism with environmental consumption as the core is the future development tendency of tourism. Tourism environment is closely linked with the development of tourism. Once relationship between tourism environmental protection and sustainable development of tourism is well solved, it will be turned into a kind of growth pattern for tourism, which will help to realize sustainable and healthy development of tourism. 


\section{Development of tourism will promote tourism environmental protection}

Sustainable and healthy development of tourism will help to popularize knowledge of environmental protection, improve the public' $s$ awareness of environmental protection, guide people to develop their ideas from yearning for the nature and approaching the nature into cherishing and protecting the nature, then realize the purpose of mutual promotion between tourism and tourism environment. From another perspective, development of tourism with virtuous circle will replace a big part of traditional industries with high consumption and serious pollution; development of the tertiary industry will increase employment rate, reduce pollution emissions and loss of zoology per gross national product, and boost the development and construction of environmental protection. Meanwhile, development of tourism will offer material basis for tourism environmental protection. Popularity, economic power and influence of the local will be improved through the development of tourism, then sufficient capital will be gained to support environmental protection, especially for infrastructure construction such as road and virescence; this will be good for constructing afforestation of city, and realize the purpose of environmental protection.

\section{Role played by tourism environmental protection in the sustainable development of tourism and related value of tourism environmental protection}

Development of tourism and tourism activities will be realized only when there is a certain spacial scale, natural environment and social environment. Environment for tourism refers to the spacial environment for tourists to place themselves in it such as scenic areas and spots; it could be divided into macro environment and micro environment; macro environment means the surrounding, and micro environment refers to the space in the surrounding. No matter it is macro environment or micro environment, quality of environment directly decides the value of objects of tourism and the development of local tourism. The beautiful environment will highlight the theme and features of objects of tourism, then enhance the attraction of objects of tourism; on the contrary, bad environment will depreciate the value of tourism. Therefore, tourism environmental protection is the effective method to promote the sustainable development of tourism. Enhance the protection on tourism environment and abide by the following principles to make objects of tourism have virtuous circle, enhance value of objects of tourism, then boost the sustainable development of tourism.

\section{Reasonable principles for planning}

In the course of developing tourism resources, local population, economy and environment should be taken into consideration. Analyze current status of local tourism resources to decide its future development trend. Evaluate the long-term carrying capacity of local environment to arrange tourist facilities and decide tourists flow accordingly, which will help to avoid over-development due to short-term profit, and avoid the unbalance between tourism environment and development of tourism.

\section{Principle of adjusting measures to local conditions}

In the course of developing tourism resources, respect the nature and follow natural law, choose reasonable development modes based on structure and features of local natural ecological environment, adopt a series of measures to protect ecologically vulnerable areas or environmental sensitive areas or precious natural landscapes, strictly control tourists flow within the natural reserve, standardize tourism activities to realize the purpose of protecting tourism environment.

\section{Core principles of protection}

In the course of developing tourism resources, take tourism environmental protection as the core; exploit tourism resources based on environmental protection; pay attention to the unification among economy, environment and social benefit; evaluate value and development of tourism from the perspective of environmental protection; reduce pollution in tourism area; build facilities for ecological protection; formulate reasonable management mechanism, and improve environment management ability of the object of tourism to realize the purpose of protecting tourism environment. 


\section{Tourism environmental protection ways based on the sustainable development of tourism}

To promote the sustainable development of tourism, it should intensify tourism environmental protection; start from development of tourism, tourism management, tourism behaviors and tourism supervision; synthesize rights and liabilities of various departments; build environmental awareness; increase supervision; implement various measures of tourism environmental protection; and actually boost the sustainable and healthy development of tourism.

\section{Develop tourism resources reasonably}

Tourism resources are the core of the development of tourism. Overdeveloping tourism resources will bring short-term benefit, but it is a kind of destruction for tourism in the long run. Therefore, to promote the sustainable development of tourism, it should develop tourism resources reasonably and build tourism accommodation based on the carrying capacity of tourism environment. On the one hand, it should exploit tourism resources as planned; it should first do field visit and data analysis to formulate scientific and reasonable development program of tourism resources to develop tourism step by step and avoid serious destruction caused by unorganized development. On the other hand, it should develop tourism resources scientifically, do several feasibility analysis on the development program; large-scale tourist facilities such as hotel should be built in the area far away from natural reserve, and only provide simple but characteristic rest areas in the natural reserve to avoid related destruction. Meanwhile, core zone of the natural reserve should not have high way to protect the natural reserve; regarding non-renewable resources, a series of protection measures should be adopted to avoid the damage of natural landscape and the irretrievable loss to reach the best effect of tourism environmental protection.

\section{Perfect tourism management system}

In the course of developing operating activities, it should save energy as much as possible, educate tourists with the reasonable and effective methods, help tourists to unconsciously have environmental awareness, and make them bear the obligation to realize the sustainable development of tourism. Therefore, no matter it is travel agency or tourism company, they shall adopt environmental protection measures to protect tourism environment and promote the sustainable development of tourism. 1) Offer environment-friendly tourism products which contain ecological tourism, agricultural tourism and forest tour; enhance the role of environmental protection in enterprise operation, then develop it into self-awareness to make contribution to tourism development in China. 2) Choose scenic areas with conditions of ecological tourism. When organizing tourism, travel agency should keep away from the vulnerable or sensitive regions and scenic areas which fail to pay attention to protection, and strictly control visits flow to avoid that tourists flow exceed the carrying capacity of the environment. 3) Guide tourists to do correct tourism or consumption behaviors, enhance tourists' environmental awareness, broadcast videos about environmental protection, provide manuals about environmental protection for tourists, intensify education related to environmental protection to tourists to implement obligation of environmental protection. 4) Hold training related to tourism environmental protection for tour guides or leaders at regular intervals to enrich professional knowledge of ecological tourism, spread environmental protection knowledge, help tourists to have environmental awareness unconsciously, then to promote the sustainable and healthy development of tourism. Furthermore, tourist hotels should respond to environmental protection to use energy-saving type equipment, reduce energy consumption, save water, popularize clean energy, avoid air environmental pollution, treat organic refuse reasonably, and do work related to environmental protection to realize tourism environmental protection and win-win between economic benefit and environmental benefit.

\section{Standardize tourism consumption behaviors}

To implement measures for tourism environmental protection, it should further standardize visitors' consumption behaviors, and improve tourists' environmental awareness and awareness 
of self-discipline to make a contribution to the sustainable development of tourism. Tourists should know their purpose of tourism, focus on learning local culture, take learning and understanding local culture as the purpose, and take part in various activities within the allowed band of environment; act as a civilized tourist; do not drop litter carelessly; avoid pollution caused by rubbishes such as plastics, peel or scraps of paper, which will threaten the sustainable development of tourism. On tour, tourists shall have environmental awareness, abide by various regulations to protect environment, drop rubbishes into dustbin or take rubbishes along with them if there is no dustbin, do not use disposable lunch box or chopsticks, actively participate in environmental protection activities to have environmental awareness and facilitate the sustainable and healthy development of tourism.

\section{Intensify tourism supervision}

As a kind of comprehensive industry, tourism involves various aspects. To protect tourism environment, national regulatory agencies of tourism and related government sectors shall carry out their responsibility of supervision; effectively supervise links such as resources development and operation control; perfect regulations and laws to ensure the sustainable development of tourism; implement principles of environmental protection; punish actions of pollutant emission and usage of hazardous substance; abide by principles of sustainable development; check current policies and regulations related to environmental protection; learn the existing problems of current policies and regulations system; evaluate and revise policies and regulations timely; enhance legal supervision on tourism to form legal protection barrier for tourism environment. Meanwhile, hold training and education related to environmental protection for management organizations and enterprises related to tourism or practitioners of tourism at regular intervals. According to character and scope of sustainable development, deepen education system; constantly improve environmental awareness of related organizations, units and practitioners; intensify idea of sustainable development and tourism behaviors, then to ensure that measures of environmental protection could be carried out consciously. Furthermore, formulate and perfect the sustainable development planning of tourism. In the course of formulating strategies of sustainable development, it should analyze future development trend of tourism from the perspective of environmental suitability to realize harmonious development between tourism development and environmental protection. For example, when develop new tourist area, it should build sewage treatment plant, protect local landform and natural vegetation, abide by principles of rational exploitation, and develop tourism resources by adjusting measures to local conditions. Regarding natural reserve, different classes shall be set based on its vulnerability and significance, and such classes contain core conservation union, laboratory areas for production and neutral zone. Rationally formulate safeguard procedures and degrees of protection, build stratified tourism environmental protection system, improve effect of tourism environmental protection, enhance value of objects of tourism to promote the sustainable development of tourism.

\section{Conclusions}

In conclusion, to promote the sustainable and healthy development of tourism, it should enhance tourism environmental protection, reasonably exploit tourism resources, perfect tourism operation system, standardize tourists' consumption behaviors, and intensify supervision on tourism. Build stratified tourism environmental protection system based on the protection class of conservation area and implement various measures related to tourism environmental protection to unite various aspects, constantly increase the value of tourist area, coordinate relationship between environmental protection and economic growth, and finally realize the sustainable and healthy development of tourism in China.

\section{References}

[1] LI M, WU B, CAIL P. Tourism development of world heritage sites in China: a geographic perspective[J]. Tourism Management, 2007:1-12. 
[2] KO T G Development of a tourism sustainability assessment procedure: a conceptual approach [J]. Tourism Management, 2005(26):431-445. 